\title{
Hakikat Hubungan Manusia dengan Tuhan dalam Perspektif Masyarakat Sasak: Kajian Etnolinguistik
}

\author{
Lukmanul Hakim*)
}

\begin{abstract}
Abstrak
Setiap masyarakat pasti memiliki cara pandang atau pandangan hidup sendiri-sendiri, tidak terkecuali masyarakat Sasak Lombok. Mengingat begitu beragamnya ekspresi kebudayaan yang disebabkan oleh pandangan hidup yang berbeda-beda pada masyarakat Lombok, penelitian ini hanya akan fokus untuk membahas dan menguraikan pandangan hidup orang Sasak di Lombok tentang hakikat hubungan manusia dengan Tuhan yang tercermin dalam bahasa atau ungkapan yang mereka pergunakan dalam kehidupan sehari-hari.

Hasil penelitian ini menunjukkan bahwa masyarakat Sasak sangat mengangungkan dan menghormati Tuhan. Di antara bentuk pengormatan mereka kepada Tuhan adalah penggunaan bahasa halus jika bahasa tersebut berhubungan dengan Tuhan.
\end{abstract}

Kata Kunci: ekspresi kebudayaan, pandangan hidup, hakikat hubungan

\section{Pengantar}

Cara pandang atau pandangan hidup adalah konsep atau cara pandang manusia yang bersifat mendasar tentang diri dan dunianya yang menjadi panduan untuk meraih kehidupan yang bermakna. Cara pandang tersebut berfungsi sebagai sarana untuk merespon dan menerangkan permasalahan eksistensial kehidupan seperti, Tuhan, manusia, dan dunia/alam semesta (Melayuonline.com, 2008).

Setiap masyarakat pasti memiliki cara pandang atau pandangan hidup sendiri-sendiri, tidak terkecuali masyarakat masyarakat Sasak Lombok. Masyarakat Sasak sebagai sebuah identitas kultural, biasanya

\footnotetext{
*) Sarjana Agama, Pembantu Pimpinan pada Kantor Bahasa Provinsi NTB
} 
diasosiasikan dengan orang yang beragama Islam, beradat istiadat Sasak, dan menempati kawasan Pulau Lombok. Defenisi semacam ini bersifat reduktif karena tidak semua orang yang mengidentifikasi dirinya sebagai orang Lombok menganut agama Islam dan mempraktikkan adat istiadat Sasak. Terdapat beberapa etnis minoritas yang beragama non-Islam dan tidak mempraktikkan adat istiadat Sasak di Lombok, di antaranya etnis Bali, Mbojo, Samawa, Jawa, Arab, Cina, Bugis, Selayar, dan Bajo, yang tersebar di Pulau Lombok. Hal ini memberikan gambaran bahwa masyarakat Lombok bukanlah sebuah entitas kebudayaan yang tunggal dan homogen. Lombok ibarat rumah, yang di dalamnya dihuni oleh berbagai orang dengan cara pandang yang berbeda-beda, baik itu yang bersumber dari perbedaan sistem religi maupun keyakinan. Sistem religi dan keyakinan tersebut memungkinkan munculnya perbedaan-perbedaan dalam hal adat-istiadat dan ritual, konsepsi kosmologi dan waktu, sistem mata pencaharian dan lain-lain.

Mengingat begitu beragamnya ekspresi kebudayaan yang disebabkan oleh pandangan hidup yang berbeda-beda pada masyarakat Lombok, penelitian ini hanya akan fokus untuk membahas dan menguraikan pandangan hidup orang Sasak di Lombok tentang hakikat hubungan manusia dengan Tuhan yang tercermin dalam bahasa atau ungkapan yang mereka pergunakan dalam kehidupan sehari-hari.

Pembicaraan tentang cara pandang atau pandangan hidup tidak akan terlepas dari teori yang diungkapkan oleh Sapir-Whorf. SapirWhorf (dalam Widhiarso, 2005:2) membuat dua buah hipotesis tentang bahasa dan pikiran, yaitu linguistic relativity hypphotesis dan linguistic determinism. Hipotesis pertama menyatakan bahwa perbedaan struktur bahasa secara umum paralel dengan perbedaan kognitif nonbahasa. Perbedaan bahasa menyebabkan perbedaan pikiran orang yang 
menggunakan bahasa tersebut, sedangkan hipotesisi kedua menyatakan bahwa struktur bahasa memengaruhi cara individu mempersepsikan dan menalar dunia. Dengan kata lain, struktur kognisi manusia ditentukan oleh kategori dan struktur yang sudah ada dalam bahasa.

Berkaitan dengan teori di atas, Widhiarso (2005:15) menyatakan tiga hal penting yang berkaitan dengan teori tersebut. Pertama, bahasa berfungsi memfasilitasi dalam hal menalar dan bukan sebagai penentu mutlak penalaran. Kedua, proses satu arah yang dicetuskan oleh SapirWhorf sebaiknya diubah menjadi dua arah, yaitu cara pandang manusia terhadap dunianya dipengaruhi oleh bahasa dan sebaliknya. Ketiga, studi atau kajian terhadap bahasa yang berbeda dalam mencerminkan pikiran penuturnya yang berbeda lebih diarahkan pada pengidentifikasian keragaman bahasa dan budaya.

Berdasarkan pernyataan Widhiarso di atas, peneliti lebih cenderung memilih tentang determinasi bahasa terhadap pikiran, yaitu bahasa merupakan sebuah media yang memfasilitasi potensi dalam menalar dan bukan sebagai penentu mutlak. Dengan kata lain, cara pandang komunitas Sasak di Lombok dapat dilihat dari bahasa atau ungkapan-ungkapan yang mereka gunakan atau bahasa merupakan cerminan dari cara pandang penuturnya terhadap hakikat hubungan manusia dengan Tuhan. Pandangan ini bersesuaian dengan apa yang dinyatakan oleh Djojosuroto (2007:272) bahwa bahasa bukan saja merupakan bentuk dari isi penuturan, melainkan juga merupakan alat atau instrumen dari proses berpikir. Di samping itu, bahasa juga bukan hanya merupakan alat mati dari pikiran. Di luar logika, bahasa mempunyai peranan-peranan lain di bidang kehidupan manusia. Dengan demikian, penggunaan media bahasa sebagai media utama untuk 
mengetahui cara pandang komunitas Sasak di Lombok terhadap dunianya adalah tepat.

Wujud data yang dijadikan bahan analisis dalam penelitian ini ada dua jenis, yaitu data yang berhubungan dengan perilaku nonverbal dan data yang berhubungan dengan perilaku verbal.

Data perilaku nonverbal memiliki dua sifat, yaitu data sekunder dan data primer. Data sekunder merupakan data yang berupa bahan pustaka yang menguraikan tentang perilaku masyarakat Sasak di Lombok, sedangkan data primer merupakan data yang diperoleh dari hasil wawancara dengan responden yang menyangkut sikap dan pandangan mereka tentang hakikat hubungan manusia dengan Tuhan.

Data verbal lebih bersifat primer, yaitu berupa data kebahasaan yang diperoleh dari tuturan komunitas Sasak di Pulau Lombok, baik berupa leksikon maupun ungkapan-ungkapan yang mereka pergunakan dalam kehidupan sehari-hari.

Dari wujud data di atas, dapat dijelaskan wujud metode yang digunakan dalam penelitian ini, baik metode yang digunakan pada waktu pengumpulan data maupun pada tahap analisis data.

Pengumpulan data perilaku nonverbal yang bersifat sekunder dilakukan melalui kajian pustaka dengan memanfaatkan hasil dokumentasi atau tulisan yang menggambarkan perilaku masyarakat Sasak di Pulau Lombok. Adapun untuk data nonverbal yang bersifat primer dilakukan dengan cara peneliti mewawancarai (wawancara mendalam) informan. Wawancara berkisar tentang sikap dan pandangan mereka tentang hal-hal yang berhubungan dengan hakikat hubungan manusia dengan Tuhan.

Selanjutnya, data perilaku verbal dikumpulkan dengan mewawancarai informan di lapangan. Wawancara difokuskan dengan 
sistem pancingan, yang diharapkan muncul terminologi kebahasaan yang berhubungan dengan unsur-unsur universal yang menentukan orientasi budaya manusia di atas.

Data yang terkumpul, dianalisis dengan analisis kualitatif, yaitu analisis yang mendasarkan diri bukan pada paradigma metodologis deduktif, tetapi induktif. Suatu paradigma yang bertitik tolak dari yang khusus ke yang umum, bukan dari yang umum ke yang khusus seperti yang terjadi dalam paradigma berpikir deduktif. Konseptualisasi, kategorisasi, dan deskripsi dikembangkan atas dasar kejadian (incidence) yang terjadi di lapangan. Teorisasi yang memperlihatkan pertalian hubungan antarkategori (antarvariabel untuk istilah dalam penelitian kualitatif) juga dikembangkan atas dasar data yang diperoleh di lapangan. Oleh karena itu, dalam penelitian kualitatif kegiatan pengumpulan data merupakan kegiatan yang berlangsung secara simultan dengan kegiatan analisis data. Prosesnya berbentuk siklus, bukan linier. Hal ini tentu tidak lepas pula dari hakikat penelitian kualitatif yang bertujuan untuk memahami fenomena sosial budaya. Oleh karenanya, analisis kualitatif fokusnya pada penunjukan makna, deskripsi, penjernihan dan penempatan data pada konteksnya masing-masing dan seringkali melukiskannya dalam bentuk kata-kata daripada dalam angka-angka.

Terdapat banyak metode yang digunakan dalam analisis kualitatif, khususnya untuk bidang ilmu sosial. Untuk keperluan kajian ini, metode analisis yang digunakan adalah metode komparatif konstan.

Dalam praktiknya, penerapan metode ini dilakukan melalui dua kegiatan, yaitu kegiatan pencatatan (coding) dan kegiatan memberi komentar terhadap catatan tersebut. Analisis dimulai dengan mencatat setiap fenomena sikap atau pandangan responden tentang hakikat hidup, 
hakikat karya, dan hakikat pandangan terhadap keberadaan manusia dalam dimensi waktu.

Selanjutnya, peneliti mulai membandingkan fenomena tersebut dengan perilaku verbal, yaitu berupa data-data kebahasaan yang mencerminkan pandangan terhadap hakikat hubungan manusia dengan Tuhan. Kesejajaran antara sistem budaya yang tercermin dalam pandangan responden dengan sistem budaya yang tercermin dalam sistem bahasanya akan dijadikan landasan untuk membuat simpulan tentang perilaku budaya komunitas Sasak di Pulau Lombok.

Desa yang dipilih menjadi daerah pengamatan adalah desa yang merupakan representasi dialek-dialek bahasa Sasak. Desa-desa tersebutv adalah Desa Kelebuh, Kecamatan Praya Tengah, Kabupaten Lombok Tengah yang penuturnya sebagian besar berdialek ě-ě, Desa Tembeng Putik, Kecamatan Wanasaba, Kabupaten Lombok Timur yang sebagian besar penuturnya berdialek a-ě, dan Desa Gondang, Kecamatan Gangga Kabupaten Lombok Utara yang sebagian besar penuturnya berdialek a-a.

\section{Pembahasan}

\subsection{Perolehan Data}

Berdasarkan hasil pengumpulan data di daerah-daerah pengamatan yang menjadi sampel penelitian, diperoleh data kebahasaan yang berkaitan dengan pandangan masyarakat Sasak di Lombok tentang hakikat hubungan manusia dengan Tuhan. Untuk lebih jelasnya dapat dilihat pada tabel di bawah ini. 


\section{Data Kebahasaan Hakikat Hubungan Manusia dengan Tuhan dalam Perspektif Masyarakat Sasak}

\begin{tabular}{|c|c|c|c|}
\hline No. & Data & Uraian/Makna & Keterangan \\
\hline 1. & Neneq & sesuatu yang tinggi & $\begin{array}{l}\text { nama Tuhan di kalangan } \\
\text { masyarakat Sasak }\end{array}$ \\
\hline 2. & Neneq wikan & Tuhan mengetahui & \\
\hline 3. & $\begin{array}{l}\text { Neneq } \\
\text { nyerminan }\end{array}$ & Tuhan melihat & \\
\hline 4. & Neneq pirengan & Tuhan mendengar & \\
\hline 5. & $\begin{array}{l}\text { pekayunan } \\
\text { Neneq }\end{array}$ & kemauan Tuhan & \\
\hline 6. & Manik Neneq & firman Tuhan & \\
\hline 7. & panjak Neneq & budak Tuhan & \\
\hline 8. & Berebeng & memberi & \\
\hline 9. & Pauman & $\begin{array}{l}\text { gotong royong } \\
\text { membangun rumah }\end{array}$ & $\begin{array}{l}\text { biasanya tuan rumah hanya } \\
\text { menyediakan bahan-bahan } \\
\text { bangunan dan konsumsi }\end{array}$ \\
\hline 10. & Banjar & $\begin{array}{l}\text { membantu orang yang } \\
\text { akan melangsungkan } \\
\text { perkawinan }\end{array}$ & $\begin{array}{l}\text { bantuan bisa berupa uang atau } \\
\text { bahan makanan }\end{array}$ \\
\hline 11. & Belangar & $\begin{array}{l}\text { membantu orang yang } \\
\text { sedang mengalami } \\
\text { musibah kematian }\end{array}$ & \\
\hline 12. & Langaran & $\begin{array}{l}\text { sumbangan orang-orang } \\
\text { yang melayat }\end{array}$ & $\begin{array}{l}\text { bantuan biasanya berupa } \\
\text { bahan makanan pokok (beras) }\end{array}$ \\
\hline 13. & dengan pacu & $\begin{array}{l}\text { orang yang taat kepada } \\
\text { Tuhan }\end{array}$ & \\
\hline 14. & dengan jadik & $\begin{array}{l}\text { orang yang tidak taat dan } \\
\text { kurang ajar kepada Tuhan }\end{array}$ & \\
\hline 15. & Sembayang & ibadah sembahyang & \\
\hline 16. & batu sembayang & $\begin{array}{l}\text { batu yang disusun } \\
\text { sedemikian rupa yang } \\
\text { biasanya berada di pinggir } \\
\text { kali dan dipakai sebagai } \\
\text { alas ibadah sembahyang }\end{array}$ & \\
\hline 17. & Wiridan & $\begin{array}{l}\text { sekumpulan doa yang } \\
\text { disusun oleh organisasai } \\
\text { keagamaan tertentu }\end{array}$ & $\begin{array}{l}\text { Doa ini biasanya dibaca } \\
\text { bersama-sama oleh pengikut } \\
\text { suatu organisasi keagamaan } \\
\text { secara terjadwal }\end{array}$ \\
\hline 18. & Besentulak & $\begin{array}{l}\text { acara memanjatkan doa } \\
\text { pembacaan kalimat- } \\
\text { kalimat zikir kepada Tuhan }\end{array}$ & \\
\hline 19. & $\begin{array}{l}\text { sikiran dengan } \\
\text { mate }\end{array}$ & $\begin{array}{l}\text { menzikirkan orang yang } \\
\text { sudah meninggal dunia }\end{array}$ & \\
\hline 20. & Nelu & $\begin{array}{l}\text { menzikirkan orang yang } \\
\text { sudah meninggal dunia } \\
\text { pada malam ke-3 }\end{array}$ & \\
\hline
\end{tabular}




\begin{tabular}{|c|l|l|l|}
\hline 21. & Mituq & $\begin{array}{l}\text { menzikirkan orang yang } \\
\text { sudah meninggal dunia } \\
\text { pada malam ke-7 }\end{array}$ & \\
\hline 22. & Nyiwaq & $\begin{array}{l}\text { menzikirkan orang yang } \\
\text { sudah meninggal dunia } \\
\text { pada malam ke-9 }\end{array}$ & \\
\hline 23. & metang dase & $\begin{array}{l}\text { menzikirkan orang yang } \\
\text { sudah meninggal dunia } \\
\text { pada malam ke-40 }\end{array}$ & \\
\hline 24. & Nyatus & $\begin{array}{l}\text { menzikirkan orang yang } \\
\text { sudah meninggal dunia } \\
\text { pada malam ke-100 }\end{array}$ & \\
\hline 25. & Nyeribuq & $\begin{array}{l}\text { menzikirkan orang yang } \\
\text { sudah meninggal dunia } \\
\text { pada malam ke-1000 }\end{array}$ & $\begin{array}{l}\text { Sekarang, acara ini sudah } \\
\text { jarang dilakukan oleh } \\
\text { masyarakat Sasak }\end{array}$ \\
\hline 26. & Behaluat & $\begin{array}{l}\text { mengheningkan diri di } \\
\text { tempat yang sepi untuk } \\
\text { memikirkan hakikat diri } \\
\text { dan kebesaran Tuhan }\end{array}$ & \\
\hline
\end{tabular}

\subsection{Perspektif Masyarakat Sasak tentang Hakikat Hubungan Manusia dengan Tuhan}

Kondisi masyarakat Sasak yang mayoritas beragama Islam menyebabkan perspektif masyarakat Sasak tentang hakikat hubungan manusia dengan Tuhan sangat dipengaruhi oleh ajaran agama Islam. Hal ini bisa dilihat dari cukup banyaknya istilah-istilah kebahasaan di kalangan masyarakat Sasak yang berkaitan dengan hakikat hubungan manusia dengan Tuhan.

Umumnya orang Sasak menyebut nama Tuhan dengan sebutan Neneq. Kata Neneq berarti sesuatu yang tinggi. Dengan demikian, Tuhan dalam perspektif masyarakat Sasak adalah sesuatu yang tinggi dan agung. Oleh karena itu, Tuhan itu tidak akan mungkin bisa dilihat, diraba, dibayangkan, dan dijangkau oleh akal pikiran manusia. Tidak ada sesuatu apa pun yang bisa menyamai-Nya. Tuhan memiliki sifat-sifat sempurna, di antaranya: 1). maha sempurna dalam segala hal, tidak mungkin dihinggapi kekurangan; 2). maha melihat semua perbuatan makhluk yang diciptakan-Nya, baik yang lahir maupun yang batin; 3). 
maha mengetahui semua perbuatan maupun perkataan makhluk yang diciptakan-Nya, baik yang lahir maupun yang batin, termasuk semua rahasia yang diciptakan-Nya; 4). maha mendengar semua suara, baik yang diucapkan secara keras maupun secara pelan, baik yang terangterangan maupun yang rahasia.

Karena Tuhan memiliki sifat-sifat di atas, semua perbuatan, perkataan, niat, dan rahasia manusia yang sudah, sedang maupun yang akan datang pasti diketahui, dilihat, dan didengar oleh Tuhan. Tidak ada tempat yang tidak terjangkau oleh pengetahuan, penglihatan, dan pendengaran Tuhan. Keyakinan seperti ini terpatri kuat di dalam hati masyarakat Sasak.

Masyarakat Sasak adalah masyarakat yang religius dan sangat mengangungkan dan menghormati Tuhan. Hal ini bisa dilihat dari bahasa atau ungkapan yang digunakan oleh masyarakat Sasak yang berkaitan dengan Tuhan. Masyarakat Sasak selalu menggunakan bahasa atau ungkapan halus jika bahasa atau ungkapan tersebut berhubungan dengan Tuhan. Di antara contoh penggunaan bahasa yang sering digunakan oleh masyarakat Sasak yang berhubungan dengan Tuhan adalah Neneq no wikan 'Tuhan itu mengetahui', Neneq no nyerminan 'Tuhan itu melihat', Neneq no pirengan 'Tuhan itu mendengar', pekayunan Neneq 'kemauan Tuhan', dan manik Neneq 'firman Tuhan'. Sebaliknya, masyarakat Sasak akan berusaha menghindari bahasa atau ungkapan tidak halus ketika bahasa atau ungkapan tersebut berhubungan dengan Tuhan. Oleh karena itu, jarang kita mendapati masyarakat Sasak mengatakan Neneq no ketaon 'Tuhan itu mengetahui', Neneq no begitaq 'Tuhan itu melihat', Neneq no bedengah 'Tuhan itu mendengar', kemeleq Neneq 'kemauan Tuhan', dan unin Neneq 'kata Tuhan'. Jika ada masyarakat yang menggunakan bahasa atau ungkapan tidak halus yang berhubungan 
dengan Tuhan, yang bersangkutan dikatakan dengan jadik 'orang yang tidak tahu adat dan kurang ajar kepada Tuhan'.

Sedangkan manusia menurut persepsi masyarakat Sasak adalah salah satu makhluk ciptaan Tuhan. Karena manusia merupakan ciptaan Tuhan, manusia tidak akan mungkin sama dengan Tuhan. Manusia memang memiliki sifat-sifat yang dimiliki oleh Tuhan, seperti mengetahui, mendengar, dan melihat. Namun, pengetahuan, pendengaran, dan penglihatan manusia tidak akan mungkin menyamai pengetahuan, pendengaran, dan penglihatan Tuhan. Manusia itu selalu bersifat lupa, khilaf, kekurangan, dan tidak sempurna seperti Tuhan.

Manusia diciptakan Tuhan dengan tujuan yang mulia dan sama sekali bukan untuk main-main. Tuhan menciptakan manusia tidak lain adalah agar manusia mengabdikan hidup kepada-Nya. Hal ini sesuai dengan ungkapan masyarakat Sasak yang menyatakan bahwa manusia pada hakikatnya adalah panjak 'budak' Tuhan. Karena manusia adalah panjak 'budak' Tuhan, manusia harus menaati semua perintah Tuhan dan menjauhi larangan-Nya. Dengan demikian, dalam menjalani kehidupan di atas dunia ini manusia harus mematuhi pedoman dan petunjuk Tuhan yang telah disampaikan kepada umat manusia.

Mengenai nasib atau takdir, masyarakat Sasak meyakini bahwa manusia tidak akan bisa mengubah nasibnya karena nasibnya sudah ditentukan oleh Tuhan. Namun demikian, manusia wajib untuk berusaha/berikhtiar untuk mengetahui ketentuan-ketentuan Tuhan yang berkaitan dengan nasibnya. Di samping berusaha, manusia juga diwajibkan untuk berdoa. Semua pekerjaan manusia, termasuk di dalamnya berusaha dan berdoa merupakan bentuk pengabdian kepada Tuhan. Semua takdir yang berasal dari Tuhan hanyalah berupa kebaikan 
kepada manusia, tetapi manusia kadang-kadang menginginkan kejelekan dengan mengerjakan hal-hal yang dilarang oleh Tuhan.

Yang dikehendaki oleh Tuhan adalah manusia yang menjadi panjak 'budak' Tuhan yang baik dan taat, giat mengabdi kepada-Nya, dan yang menyerahkan diri secara total kepada Tuhan dengan melaksanakan apa yang menjadi perintah-Nya dan menjauhi semua larangan-Nya. Pengabdian kepada Tuhan bisa berupa aktivitas-aktivitas ritual yang dilakukan dengan penuh hikmat dan pemahaman, seperti salat, zakat, puasa, haji, dan zikir. Pengabdian kepada Tuhan juga bisa berupa aktivitas-aktivitas yang mendatangkan kemashalatan bagi orang lain, seperti berebeng 'membantu orang lain', belangar 'membantu orang yang sedang mengalami musibah kematian', pauman 'gotong royong membangun rumah', dan banjar 'membantu orang yang akan melangsungkan perkawinan'. Dengan demikian, manusia yang dikehendaki Tuhan adalah manusia yang pacu 'taat' beribadah dan yang peduli dengan orang lain.

Orang yang pacu 'taat' beribadah dan berbuat baik kepada sesama sangat disukai oleh Tuhan dan manusia. Di samping itu, manusia yang demikian akan mengalami kehidupan yang aman, sejahtera lahir dan batin, baik di dunia maupun pada kiamat nanti. Sebaliknya orang yang jadik 'tidak taat' dan tidak berbuat baik kepada sesama akan dimurkai Tuhan dan manusia. Di samping itu, manusia yang demikian akan mengalami kehidupan yang hina dan nista, baik di dunia maupun pada hari kiamat nanti.

\subsection{Implikasi Kepercayaan Sasak terhadap Tuhan}

Implikasi kepercayaan masyarakat Sasak tersebut terhadap Tuhan dapat kita lihat dalam sikap keseharian mereka, baik terhadap diri mereka 
sendiri maupun kepada orang lain. Di antara implikasi yang ditimbulkan terhadap kepercayaan terhadap Tuhan tersebut dalam kehidupan seharihari sebagai berikut.

1. Masyarakat Sasak dalam kegiatan sembahyang

Sembahyang adalah ritual ibadah yang sangat diutamakan oleh masyarakat Sasak, terutama sembahyang wajib sebanyak 5 kali sehari semalam. Masyarakat Sasak selalu menyempatkan diri untuk menunaikan ibadah tersebut sesibuk apa pun mereka, baik ketika mereka berada di rumah maupun di tengah perjalanan. Hal ini disebabkan adanya anggapan di kalangan masyarakat Sasak bahwa sembahyang adalah kewajiban yang harus dikerjakan. Bila sembahyang tidak dikerjakan, ada perasaan berdosa dan perasaan bersalah di kalangan masyarakat Sasak.

Mereka biasanya menunaikan ibadah sembahyang di masjid atau musala, baik secara sendirian maupun bersama/berjamaah. Kalau ibadah sembahyang tidak dimungkinkan untuk ditunaikan di masjid atau mushalla, masyarakat Sasak bisa menunaikannya di tempat-tempat lain yang bersih dan suci. Tempat-tempat lain yang bisa digunakan sebagai tempat menunaikan salat antara lain berugaq, ruang tamu, atau batu sembayang 'batu yang disusun sedemikian rupa yang biasanya berada di pinggir kali'.

Karena ibadah sembahyang termasuk perbuatan yang sangat mulia dan sangat diutamakan di kalangan masyarakat Sasak, orang yang rajin sembahyang akan sangat dihormati. Sebaliknya, orang yang tidak rajin atau jarang melakukan sembahyang dianggap orang yang hina dan tidak layak dihormati.

2. Masyarakat Sasak dalam kegiatan keagamaan

Berdoa kepada Tuhan biasa dilakukan oleh masyarakat Sasak ketika mereka meminta sesuatu kepada Tuhan atau ketika mereka 
mengharapkan berkah dari acara yang mereka selenggarakan. Bahkan terdapat semacam ritual memanjatkan doa yang dilakukan secara terjadwal. Doa ini biasanya disusun oleh sebuah organisasi keagamaan yang dibaca secara bersama-sama oleh pengikut organisasi tersebut. Terdapat banyak bentuk doa yang dilakukan masyarakat Sasak. Di antara bentuk-bentuk doa yang dilakukan masyarakat Sasak sebagai berikut.

- serakalan

Serakalan adalah acara memanjatkan doa dan pembacaan salawat kepada Nabi Muhamamad SAW. Acara ini biasanya diselenggarakan ketika ada anggota keluarga yang akan berangkat kerja ke tempat yang jauh atau ketika ada anggota keluarga yang akan menunaikan ibadah haji ke Mekah. Acara ini biasanya dihadiri oleh para tetangga dan anggota keluarga yang menyelenggarakan acara tersebut.

Maksud diadakannya acara ini agar yang pergi mencari rezeki itu selamat sampai tujuan, selamat dan sehat ketika kembali pulang dan mendapatkan rezeki yang banyak dan halal, dan yang pergi menunaikan ibadah haji tersebut selamat dan mendapatkan ibadah haji yang mabrur.

- besentulak

Besentulak adalah acara memanjatkan doa pembacaan kalimat-kalimat zikir kepada Tuhan. Acara ini biasanya diselenggarakan ketika ada warga yang sudah selesai membangun rumah dengan maksud agar rumah yang sudah dibangun tersebut terhindar dari mara bahaya dan aman dari gangguan jin atau manusia. Acara ini juga bisa diselenggarakan untuk mengirimkan doa kepada anggota keluarga yang sudah meninggal dunia dengan maksud agar dosa anggota keluarga yang sudah meninggal dunia 
tersebut diampuni oleh Tuhan. Biasanya aca ini dihadiri oleh para tetangga dan anggota keluarga yang menyelenggarakan acara tersebut.

- sikiran dengan mate 'menzikirkan orang yang sudah meninggal dunia'

Ketika ada yang meninggal dunia, masyarakat Sasak biasanya akan menyelenggarakan acara zikir bersama selama sembilan malam berturut-turut. Malam pertama sampai kesembilan dihitung sejak dimakamnya yang sudah meninggal dunia tersebut. Istilah acara zikir tersebut disesuaikan dengan malam keberapa acara zikir tersebut dilakukan. Malam ketiga acara zikir tersebut disebut nelu, malam ketujuh disebut mituq, dan malam kesembilan disebut nyiwaq.

Selain acara zikir bersama selama 9 hari berturut-turut, masyarakat Sasak juga menyelenggarakan acara zikir bersama pada malam yang ke-40, malam ke-100, dan malam ke-1000. Acara zikir bersama untuk malam yang ke-40 disebut metang dase, malam yang ke-100 disebut nyatus, dan untuk malam yang ke-1000 disebut nyeribuq.

Acara zikir bersama tersebut biasanya dihadiri oleh para tetangga dan anggota keluarga yang sudah meninggal dunia yang diselenggarakan di rumah anggota keluarga yang meninggal dunia.

Setelah acara zikir bersama selesai, biasanya yang hadir akan disuguhi makanan dan minuman. Biaya makanan dan minuman tersebut berasal dari kekayaan orang yang sudah meninggal dunia tersebut, urunan keluarga dan atau langaran 'sumbangan orang-orang yang melayat'. 
Maksud diadakannya acara ini agar semua dosa yang sudah meninggal dunia tersebut diampuni oleh Tuhan dan nanti pada hari kiamat dimasukkan ke surga.

- wiridan

Wiridan adalah acara pemanjatan doa, pembacaan salawat kepada Nabi Muhamad SAW dan ayat-ayat suci Alquran. Wiridan ini disusun oleh sebuah organisasi keagamaan, misalnya Nahdlatul Wathan (NW), Nahdlatul Ulama (NU), dan Darul Muhajirin (DM). Masing-masing massa organisasi keagamaan tersebut membaca wiridan yang disusun oleh organisasi keagamaan mereka secara terjadwal. Biasanya wiridan ini dibaca setiap malam Jumat di masjid, musala, dan santren.

Melalui media wiridan ini pembaca wiridan berharap dan berdoa kepada Tuhan agar masyarakat aman, tenteram, sehat walafiat dan nanti pada hari kiamat termasuk orang-orang yang selamat dari api neraka.

- behaluat

Yang dimaksudkan dengan behaluat adalah mengheningkan diri di tempat yang sepi untuk memikirkan hakikat diri dan kebesaran Tuhan. Haluat ini dilakukan di suatu tempat yang sepi agar yang melakukan haluat tidak terganggu oleh suara atau gerakan yang berada di sekitar.

Bentuk tempat haluat bisa berupa ruangan rumah yang terletak agak dalam atau sebuah bangunan yang berada agak jauh dari keramaian.

3. Masyarakat Sasak sangat menonjolkan simbol-simbol keagamaan

Simbol-simbol keagamaan sangat diutamakan di kalangan masyarakat Sasak. Di antara simbol keagamaan yang kita bisa 
dijumpai di mana-mana adalah bangunan masjid. Oleh karena itu, kita akan menjumpai bangunan masjid hampir di setiap dusun di Pulau Lombok. Karena sangat banyaknya masjid, Pulau Lombok terkenal dengan julukan Pulau Seribu Masjid.

Untuk membangun sebuah masjid, masyarakat Sasak tidak membutuhkan waktu yang lama. Hal ini disebabkan masyarakat Sasak sangat percaya dan yakin akan memperoleh pahala dan kemuliaan dari Tuhan jika ikut berpartisipasi dalam pembangunan sebuah masjid. Bahkan, ada kepercayaan di sebagian kalangan masyarakat Sasak bahwa nanti pada hari kiamat masjid akan difungsikan sebagai kapal terbang menuju surga oleh orang-orang yang membangunnya. Karena itu, masyarakat Sasak sangat antusias berpartisipasi dalam pembangunan sebuah masjid. Bentuk partisipasi masyarakat Sasak tersebut bisa berupa sumbangan uang, bahan bangunan, dan atau tenaga.

Masyarakat Sasak juga yakin bahwa kemegahan dan keindahan masjid yang dibangun akan mempengaruhi cinta dan sayang Tuhan kepada manusia yang membangunnya. Semakin megah dan cantik sebuah masjid yang dibangun, maka cinta dan kasih sayang Tuhan akan semakin besar kepada orang-orang yang membangunnya. Oleh karena itu, tidak mengherankan bila bangunanbangunan masjid di Pulau Lombok ukurannya besar dan megah mengalahkan bangunan-bangunan yang lain. 


\section{Penutup}

\subsection{Simpulan}

Berdasarkan data kebahasaan, Tuhan dalam perspektif masyarakat Sasak adalah sesuatu yang tinggi dan agung. Tuhan memiliki sifat-sifat yang sangat sempurna. Sebaliknya, manusia memiliki sifat-sifat yang tidak sempurna. Oleh karena itu, Tuhan harus diagungkan dan dihormati. Di antara bentuk penghormatan masyarakat Sasak kepada Tuhan adalah penggunaan bahasa halus jika bahasa tersebut berhubungan dengan Tuhan.

Manusia diciptakan Tuhan hanya untuk mengabdi kepadaNya. Bentuk pengabdian manusia kepada Tuhan bisa berupa aktivitas-aktivitas ritual yang langsung berhubungan dengan Tuhan dan aktivitas-aktivitas yang mendatangkan kemashalatan bagi orang lain.

Implikasi kepercayaan masyarakat Sasak tersebut terhadap Tuhan dapat kita lihat dalam sikap keseharian masyarakat Sasak. Di antara implikasi yang ditimbulkan terhadap kepercayaan terhadap Tuhan tersebut adalah masyarakat Sasak sangat mengutamakan ibadah sembahyang, doa-doa dan simbol-simbol keagamaan.

\subsection{Saran}

Penelitian tentang hakikat hubungan manusia dengan Tuhan etnis Sasak di Pulau Lombok dengan daerah pengamatan yang lebih luas pada masa yang akan datang perlu dilakukan. Hal ini untuk memberikan gambaran yang lebih jelas dan lebih lengkap mengenai fenomena kebahasaan dalam hubungannya dengan pandangan hidup masyarakat etnis Sasak sebagai pemakai bahasa itu sendiri. 


\section{Daftar Pustaka}

Djojosuroto, Kinayati. 2007. Filsafat Bahasa. Jakarta: Pustaka Book Publisher.

Melayuonline.com. 2008. Pandangan Hidup Melayu. Diakses tanggal 8 November 2008.

Widhiarso, Wahyu. 2005. Pengaruh Bahasa terhadap Pikiran: Kajian Hipotesis Benyamin Whorf dan Edward Sapir. Yogyakarta: Fakultas Psikologi UGM. 